\title{
SUHU DAN WAKTU HIDROTERMAL PADA SINTESIS ZSM-5 DARI METAKAOLIN
}

\author{
Hartati Hartati*, Alfa Akustia Widati, Aning Purwaningsih, Alfinda Novi Kristanti, \\ Anik Fathur Rohmah \\ Departemen Kimia, Fakultas Sains dan Teknologi \\ Universitas Airlangga \\ *email: hartati@fst.unair.ac.id
}

Received 6 Maret 2018

Accepted 2 Mei 2018

\begin{abstract}
Abstrak
Sintesis ZSM-5 dilakukan dari metakaolin terdealuminasi tanpa penambahan templat organik. Sintesis dilakukan melalui pengaturan suhu hidrotermal mulai suhu $120^{\circ} \mathrm{C}, 150^{\circ}$, dan $170^{\circ} \mathrm{C}$. Hasil sintesis dikarakterisasi dengan difraksi sinar-X, spektroskopi FTIR, dan adsorpsi/desorpsi nitrogen. Pengaturan suhu hidrotermal pada $120^{\circ} \mathrm{C}$ selama 24 jam belum menghasilkan ZSM-5, sedangkan sintesis pada suhu $150^{\circ} \mathrm{C}$ selama 24 jam telah diperoleh hasil ZSM-5. Hidrotermal pada $170^{\circ}$ juga dapat membentuk ZSM-5 dengan pengotor mordenit dan kurang kristalin dibandingkan sintesis pada $150^{\circ} \mathrm{C}$.
\end{abstract}

Katakunci: ZSM-5, metakaolin, terdealuminasi, tanpa templat, pengaturan suhu dan waktu

\begin{abstract}
Synthesis of ZSM-5 is carried out from dealuminated metakaolin without the addition of organic template. The synthesis is done by setting the hydrothermal temperature from $120^{\circ} \mathrm{C}, 150^{\circ} \mathrm{C}$, and $170^{\circ} \mathrm{C}$. The results were characterized by an X-ray diffraction, FTIR spectroscopy, and nitrogen adsorption/desorption. Hydrothermal temperature setting at $120^{\circ} \mathrm{C}$ for 24 hours has not produced ZSM-5, while the synthesis at $150^{\circ} \mathrm{C}$ for 24 hours was obtained ZSM-5. Hydrothermal at $170^{\circ} \mathrm{C}$ can still form ZSM-5 with mordenite impurities and less crystalline than synthesis at $150{ }^{\circ} \mathrm{C}$.
\end{abstract}

Keywords: ZSM-5, dealuminated metakaolin, without organic templates, temperature and time settings

\section{Pendahuluan}

Secara umum sintesis zeolit dilakukan melalui reaksi sumber silika dan alumina secara hidrothermal menggunakan templat sesuai dengan produk zeolit yang diinginkan. Sintesis ZSM-5 biasanya menggunakan templat TPAOH (Niu et.al., 2017; Liua et al., 2018) atau TPABr (Mouhiuddin et al., 2016, Ali et al., 2017, $\mathrm{Wu}$ et al., 2017). Namun demikian telah banyak pula sintesis ZSM-5 dilakukan tanpa templat organik (Didik et al., 2012; Hartati et al., 2017). Sintesis ZSM-5 tanpa templat organik saat ini lebih dipilih karena relatif lebih aman bagi lingkungan. Penggunaan templat organik pada sintesis ZSM-5 memerlukan tahapan penghilangan templat setelah produk diperoleh, yang biasanya dilakukan melalui kalsinasi. Penghilangan templat ini dapat menyebabkan polusi udara, sehingga perlu dihindari.

Sementara itu untuk sumber silika, sebagian peneliti menggunakan bahan alami seperti kaolin (Mohiuddin et al., 2016, Hartati et al., 2017, Rustam et al., 2017) atau sekam padi (Panpa, 2009, Ali et al., 2017,), sedangkan peneliti lain banyak 
yang menggunakan bahan kimia, seperti tetraetilortosilikat (TEOS) (Hartati et al., 2016, Biligetu, et al., 2017) atau Ludox (Jiao et al., 2017). Penggunan bahan alam seperti kaolin dan lain-lainnya selain lebih hemat dari sisi persiapan bahan, juga menguntungkan bagi peneliti dari negara yang masih berkembang karena pemesanan bahan biasanya memerlukan waktu yang cukup lama. Pada sisi lain, sintesis ZSM-5 dari bahan alam seperti kaolin diharapkan dapat meningkatkan nilai bahan baku agar dapat menjadi komuditas yang lebih berharga.

Penggunaan kaolin sebagai bahan baku (sumber) silika dan alumina dalam sistesis ZSM-5 biasanya melalui penambahan silika, misalnya dari TEOS (Hartati et al., 2016). Di sini kami melaporkan sintesis ZSM-5 dari metakaolin (kaolin terkalsinasi) tanpa penambahan penambahan templat organik dan tanpa penambahan silika. Untuk mencukupi rasio mol S1/Al dalam sintesis ZSM-5 dilakukan melalui dealuminasi metakaolin yang digunakan, sedangkan agar sintesis dapat dilakukan tanpa templat dilakukan melalui pengaturan suhu dan waktu hidrotermal.

\section{Metode Penelitian}

\section{Alat dan bahan}

Bahan-bahan yang digunakan dalam penelitian ini adalah kaolin alam yang diperoleh dari Kepulauan Bangka dan Belitung, asam klorida ( $\mathrm{HCl}$, Merck, $37 \%)$, natrium hidroksida ( $\mathrm{NaOH}$, Merck, 99\%) dan akuades.

\section{Prosedur \\ a. Metakaolinisasi}

Metakalolinisasi bertujuan untuk memperoleh kaolin. Kaolin Bangka Belitung dikalsinasi menggunakan furnace selama 8 jam pada suhu $650^{\circ} \mathrm{C}$. Metakaolin yang diperoleh kemudian dikarakterisasi menggunakan XRF ( $X$-ray Flourescence) dan XRD (X-ray Diffraction).

b. Dealuminasi metakaolin
Sejumlah metakaolin direfluks dengan larutan $\mathrm{HCl} 8 \mathrm{M}$ (perbandingan masa matekaolin dan volume $\mathrm{HCl}=1: 5$, pada suhu $80^{\circ} \mathrm{C}$ selama 2 jam, diperoleh M1. Dengan cara yang sama dilakukan metakaolinisasi dengan refluks menggunakan $\mathrm{HCl} 6 \mathrm{M}$, diperoleh $\mathrm{M} 2$. Produk yang diperoleh masing-masing disaring dan dicuci dengan akuades dan sentrifugasi secara berulang hingga $\mathrm{pH}$ netral. Metakaolin terdealuminasi yang diperoleh kemudian dikeringkan pada suhu $100^{\circ} \mathrm{C}$ selama 24 jam (Pan et al., 2014). Metakaolin terdealuminasi kering dikarakterisasi dengan XRF.

c. Sintesis ZSM-5 dari Metakaolin Terdealuminasi

Sebanyak 2,2 g M1 dan 0,8 g M2 dicampur dengan larutan $\mathrm{NaOH}(0,86 \mathrm{~g}$ dalam $64 \mathrm{~mL}$ akuades) dalam piala polipropilen, sehingga diperoleh campuran dengan komposisi molar 0,1 $\mathrm{SiO}_{2}: 0,008 \mathrm{Al}_{2} \mathrm{O}_{3}: 0,0215 \mathrm{NaOH}: 3,55 \mathrm{H}_{2}$ O. Campuran diaduk menggunakan pengaduk magnet dengan kecepatan 400 rpm selama \pm 5 jam pada suhu kamar. Kemudian campuran dibagi 2. Campuran 1 didiamkan pada suhu kamar selama 19 jam kemudian dipindahkan kedalam autoclave stainless steel, lalu dilakukan proses hidrotermal pada suhu $170^{\circ} \mathrm{C}$ selama \pm 5 jam. Campuran 2 didiamkan selama 24 jam pada suhu kamar. Selanjutnya campuran 1 dan 2 dicampur, kemudian campuran dilakukan proses hidrotermal dengan variasi suhu $120^{\circ} \mathrm{C}$ selama 72 jam, pada $150^{\circ} \mathrm{C}$ selam $24 ; 48$; dan 72 jam serta pada $170^{\circ} \mathrm{C}$ selam 24; 48; dan 60 jam. Produk yang terbentuk dipisahkan dari filtratnya menggunakan sentrifugasi, padatan dicuci dengan akuades hingga $\mathrm{pH}$ netral dan dikeringkan pada suhu $100^{\circ} \mathrm{C}$ selama 24 jam Selanjutnya produk dikarakterisasi menggunakan FTIR, XRD, dan adsorpsi/desorpsi nitrogen.

\section{d. Karakterisasi}

Bahan dasar penelitian, yaitu metakaolin dan kaolin terdealuminasi ditentukan komposisi kimianya menggunakan $X$-Ray Flourescence (XRF). 
Sejumlah sampel dihaluskan hingga menjadi serbuk, kemudian ditempatkan pada tempat sampel hingga sekitar $1 / 3$ dari tinggi tempat sampel dan diratakan. Selanjutnya tempat sampel yang berisi sampel dimasukkan ke dalam alat untuk diukur komposisi kimianya.

Analisis sampel dari bahan dasar dan hasil sintesis secara X-Ray Difraction (XRD) dilakukan dengan cara menempatkan sampel yang telah dihaluskan pada tempat sampel dan diratakan, lalu tempat sampel dimasukkan ke dalam alat. Sampel disinari dengan sinar-X menggunakan radiasi $\mathrm{Cu}-\mathrm{K \alpha}$ dengan rentang sudut $2 \theta=5-50^{\circ}$.

Untuk mengetahui perubahan karakteristik vibrasi kerangka zeolit hasil sintesis dilakukan dengan spektrofotometer Fourier Transform Infrared (FTIR). Kira-kira sebanyak $1 \mathrm{mg}$ sampel dihaluskan hingga menjadi serbuk yang halus menggunakan mortar agat dengan dicampurkan sekitar $100 \mathrm{mg}$ padatan $\mathrm{KBr}$. Campuran dalam bentuk serbuk ditempatkan pada preparat dan ditekan dengan alat pengepres untuk membentuk pelet yang transparan. Kemudian sampel dalam bentuk pelet dimasukkan ke dalam wadah sampel dan direkam spektrumnya dengan FTIR pada rentang bilangan gelombang $400-4000$ $\mathrm{cm}^{-1}$.

Penentuan pori sampel hasil sintesis dilakukan dengan adsorpsi/desorpsi nitrogen. Sebanyak 0,05 gram sampel divakum selama 2 jam pada suhu $150{ }^{\circ} \mathrm{C}$. Selanjutnya sampel dialiri gas $\mathrm{N}_{2}$ dan diadsorp pada temperatur yang sangat rendah $\left(77^{\circ} \mathrm{K}\right)$ dalam tekanan vakum. Luas permukaan sampel diukur dari jumlah molekul yang terdeposit (teradsorp) pada monolayer. Luas permukaan spesifik ( $\left.\mathrm{S}_{\mathrm{BET}}\right)$ dihitung dengan metode BET, sedangkan distribusi ukuran pori dianalisis dari metode $\mathrm{BJH}$.

\section{Hasil dan Pembahasan \\ Metakaolinisasi dan Metakaolin}

Metakaolinisasi merupakan proses kalsinasi kaolin menjadi metakaolin. Kaolin memiliki bentuk kristalin yang stabil secara kimiawi diubah menjadi bentuk amorf yang lebih reaktif (Ayele et al., 2015). Proses metakaolinisasi dilakukan dengan menempatkan kaolin pada tutup kurs porselen atau krus kapal dan diratakan sampai tipis $\pm 2 \mathrm{~mm}$ agar semua permukaan lapisan kaolin dapat teraliri panas. Selanjutnya kalsinasi kaolin dilakukan pada suhu $650^{\circ} \mathrm{C}$ selama 8 jam (Feng et al., 2008). Berdasarkan Johnson dan Arshad (2014), suhu kalsinasi optimum metakaolinisasi antara 600$800^{\circ} \mathrm{C}$. Kaolin yang semula berwarna putih, setelah dikonversi menjadi metakaolin berwarna putih kekuningan. Perubahan warna ini disebabkan karena rusaknya struktur lembar kaolin akibat lepasnya gugus hidroksil dari struktur kaolin (Cheng, et al., 2012). Reaksi pembentukan metakaolin atau pelepasan air pada proses metakaolinisasi ditunjukan oleh persamaan 1 .

$$
\mathrm{Si}_{2} \mathrm{O}_{5}(\mathrm{OH})_{4} \mathrm{Al}_{2} \text { (kaolin) } \rightarrow \mathrm{Al}_{2} \mathrm{Si}_{2} \mathrm{O}_{7} \text { (metakaolin) }+2 \mathrm{H}_{2} \mathrm{O}
$$

Perubahan pola difraksi dari kolin menjadi metakaolin dapat dilihat pada Gambar 1. Pola difraksi pada Gambar 1 menunjukkan bahwa kaolin memiliki puncak pada sudut $2 \theta$ sekitar $12,3^{\circ}$ dan $24,8^{\circ}$. Hasil ini sesuai dengan penelitian yang dilakukan oleh Ayele et al. (2015) yang menyebutkan puncak khas kaolin berada pada $2 \theta$ sekitar $12,34^{\circ}$ dan $24,64^{\circ}$.
Tampak perubahan pola difraksi dari kaolin ke metakaolin dari kristalin menjadi amorf, dengan puncak melebar pada sudut $2 \theta$ sekitar $23^{\circ}$. Bentuk kristal kaolin berupa lapisan-lapisan yang saling terikat akibat adanya interaksi gugus hidroksil antar lapisan. Pada saat kalsinasi, gugus hidroksil melepaskan diri dari koordinasi ion $\mathrm{Al}^{3+}$ menghasilkan air. Produk hasil 
dehidroksilasi atau metakaolinisasi adalah produk amorf yaitu metakaolin (Cheng, et al., 2012).

Komposisi metakaolin dianalisis dengan XRF yang hasilnya disajikan pada Tabel 1. Tabel 1 menunjukkan komposisi metakaolin Bangka Belitung mengandung $\mathrm{SiO}_{2}$ sebesar 54,3\% dan $\mathrm{Al}_{2} \mathrm{O}_{3}$ sebesar $38,6 \%$ sehingga rasio mol $\mathrm{SiO}_{2} / \mathrm{Al}_{2} \mathrm{O}_{3}$ sekitar 2,39. ZSM-5 merupakan zeolit dengan rasio $\mathrm{mol} \mathrm{Si} / \mathrm{Al}$ tinggi dari 10 hingga 100 (Kovo, 2011), sehingga untuk memenuhi kriteria ZSM-5 perlu peningkatan rasio mol Si/Al. Rasio mol $\mathrm{Si} / \mathrm{Al}$ dapat ditingkatkan melalui dealuminasi, yaitu proses pengurangan alumina dari kerangka metakaolin (Pan et al., 2014). Hasil XRF pada Tabel 1 menunjukkan komposisi oksida pada metakaolin sebelum dan sesudah dealuminasi. Ada dua macam perlakukan dealuminasi pada metakaolin, yang hasilnya ditunjukkan pada Tabel 1, yaitu dealuminasi dengan $\mathrm{HCl} 6 \mathrm{M}$ (M1) dan HCl 8 M (M2). Tampak pada Tabel 1 kadar alumina turun cukup tajam setelah dilakukan refluks menggunakan $\mathrm{HCl} 6 \mathrm{M}$ pada suhu $80^{\circ} \mathrm{C}$ selama 2 jam, bahkan pada refluks dengan $\mathrm{HCl} 8 \mathrm{M}$ pada suhu dan waktu yang sama dapat menghilangkan kadar alumina dari metakaolin

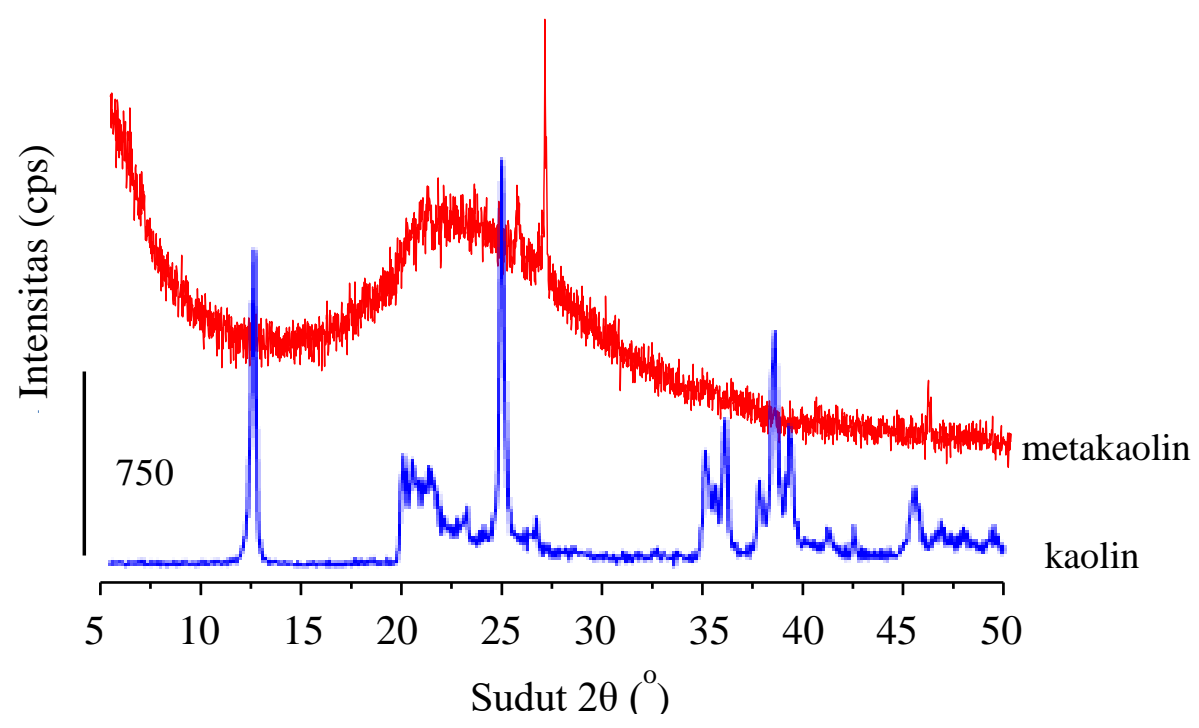

Gambar 1. Pola difraksi kaolin dan metakaolin (Hartati, et al., 2017)

Sintesis ZSM-5

Sintesis ZSM-5 dilakukan dari bahan dasar metakaolin terdealuminasi dengan metode hidrotermal. Hidrotermal dilakukan pada berbagai suhu dan waktu. Pola difraksi hasil sintesis ditunjukkan pada Gambar 2. Pada Gambar 2 ditunjukkan bahwa pola difraksi hasil sintesis dengan suhu hidrotermal $120^{\circ} \mathrm{C}$ selama 72 jam (120-72) belum menghasilkan ZSM-5, karena yang terlihat adalah puncak melebar yang khas bagi padatan amorf. Pola difraksi yang menunjukkan puncak tajam pada $2 \theta=$ $26,28^{\circ}$ menunjukkan bahwa hasil sintesis tercampur dengan kuarsa. Sementara itu hasil sintesis pada suhu $150{ }^{\circ} \mathrm{C}$ selama 24 jam menunjukkan pola difraksi dengan puncak-puncak pada $2 \theta$ sekitar 6,$01 ; 7,76$; 8,$64 ; 22,14 ; 22,87 ; 23,07 ; 23,68 ; 24,18$; 25,$55 ; 26,19 ; 26,45 ; 27,53$. Adanya puncak pada $2 \theta$ sekitar $7-8^{\circ}$ dan sekitar $23^{\circ}$ - $25^{\circ}$ menunjukkan bahwa ZSM-5 telah terbentuk (Pan et al., 2014), sedangkan beberapa puncak pada $2 \theta$ sekitar 26,19; 26,45; 27,53 merupakan kuarsa (Mohiuddin et al., 2016), dan pada sekitar 25,55 menunjukkan mordenit. Pola difraksi hasil sintesis ZSM-5 dengan suhu hidrotermal $150^{\circ} \mathrm{C}$ selama 48 jam (150-48) menunjukkan puncak pada sudut $2 \theta$ sekitar 5,$85 ; 9,62 ; 22,31 ; 23,09 ; 23,72 ; 25,68$; 
27,74; sedangkan hasil sintesis pada suhu hidrotermal $150^{\circ} \mathrm{C}$ selama 72 jam (15072) menunjukkan puncak pada sudut $2 \theta$ sekitar 5,44; 9,79; 21,72; 22,28; 25,70; 26,$33 ; 27,70 ; 27,90$. Tampak bahwa semakin lama waktu hidrotermal puncak yang menunjukkan kekhasan ZSM-5 semakin berkurang dan mulai bertumbuh kristal mordenit di samping kuarsa (Pan, et al., 2014).

Pola difraksi hasil sintesis pada suhu $170^{\circ} \mathrm{C}$ selama $24 ; 48$; dan 60 jam ditunjukkan juga pada Gambar 3. Pola difraksi hasil sintesis pada suhu $170^{\circ} \mathrm{C}$ selama 24 jam (170-24) menunjukkan puncak $2 \theta$ sekitar 12,$64 ; 18,74 ; 21,42$; 22,$38 ; 23,02 ; 24,78 ; 24,84 ; 25,44 ; 26,96$;
30,10, sedangkan hasil sintesis selama 48 jam (170-48) menunjukkan puncak pada sudut $2 \theta$ sekitar 12,58; 18,78; 21,38; 22,$34 ; 23,06 ; 24,80 ; 24,84 ; 25,40 ; 26,86$; 30,08. Difaktogram XRD sintesis ZSM-5 pada $170^{\circ} \mathrm{C}$ selama 72 jam (170-72) menunjukkan puncak pada sudut $2 \theta$ sekitar 12,$60 ; 18,80 ; 21,36 ; 22,28 ; 23,06 ; 24,82$; 24,$86 ; 25,76 ; 26,92 ; 30,14$. Dari ketiga perlakuan di atas tidak terlihat adanya karakteristik puncak ZSM-5. Hal ini dikarenakan semakin tinggi suhu hidrotermal fasa metastabil ZSM-5 akan membentuk fasa yang lebih stabil seperti mordenit dan kuarsa (Mohiuddin et al., 2016)

Tabel 1. Data XRF metakaolin dan metakaolin terdealuminasi

\begin{tabular}{|c|c|c|c|c|}
\hline \multirow[b]{2}{*}{ No. } & \multirow[b]{2}{*}{ Oksida } & \multicolumn{3}{|c|}{ Kadar (\%b/b) } \\
\hline & & Metakaolin & $\begin{array}{c}\text { Metakaolin } \\
\text { terdealuminasi (M1) }\end{array}$ & $\begin{array}{c}\text { Metakaolin } \\
\text { terdealuminasi (M2) }\end{array}$ \\
\hline 1. & $\mathrm{Al}_{2} \mathrm{O}_{3}$ & 38,60 & 13,00 & - \\
\hline 2. & $\mathrm{SiO}_{2}$ & 54,30 & 82,20 & 96,00 \\
\hline 3. & $\mathrm{~K}_{2} \mathrm{O}$ & 0,72 & 0,31 & 0,21 \\
\hline 4. & $\mathrm{CaO}$ & 0,58 & 0,35 & 0,37 \\
\hline 5. & $\mathrm{TiO}_{2}$ & 1,57 & 1,89 & 2,24 \\
\hline 6. & $\mathrm{~V}_{2} \mathrm{O}_{5}$ & 0,03 & 0,02 & 0,02 \\
\hline 7. & $\mathrm{Cr}_{2} \mathrm{O}_{3}$ & 0,05 & - & 0,31 \\
\hline 8. & $\mathrm{MnO}$ & 0,04 & 0,03 & - \\
\hline 9. & $\mathrm{Fe}_{2} \mathrm{O}_{3}$ & 3,38 & 2,00 & 0,63 \\
\hline 10. & $\mathrm{NiO}$ & 0,49 & 0,07 & 0,06 \\
\hline 11. & $\mathrm{CuO}$ & 0,08 & 0,05 & 0,04 \\
\hline 12. & $\mathrm{ZnO}$ & 0,02 & - & - \\
\hline 13. & $\mathrm{Ga}_{2} \mathrm{O}_{3}$ & 0,04 & 0,05 & - \\
\hline 14. & $\mathrm{Re}_{2} \mathrm{O}_{7}$ & 0,07 & - & - \\
\hline
\end{tabular}

Tabel 2. Bilangan gelombang vibrasi ulur dan tekuk pada sampel yang diukur dengan FTIR

\begin{tabular}{ccccccc}
\hline \multirow{2}{*}{ Sampel } & \multicolumn{9}{c}{ Vilangan gelombang $\left(\mathrm{cm}^{-1}\right)$} \\
\\
& \multicolumn{2}{c}{ Asimetri } & \multicolumn{2}{c}{ Simetri } & D5R & Tekuk \\
& eksternal & internal & Eksternal & internal & & T-O \\
\hline $120-72$ & - & 1076 & 793 & - & 546 & 457 \\
$150-24$ & 1227 & 1064 & 791 & - & 545 & 449 \\
$150-48$ & 1228 & 1042 & 791 & - & 547 & 434 \\
$150-72$ & 1228 & 1067 & 795 & - & 553 & 446 \\
$170-24$ & 1226 & 1072 & 797 & 737 & 559 & 453 \\
$170-48$ & 1228 & 1074 & 799 & 742 & 555 & 455 \\
$170-60$ & 1228 & 1064, & 777 & 694 & 557 & 457 \\
\hline
\end{tabular}

Karateristik vibrasi kerangka zeolit ditentukan dengan spektofotometer FTIR. Gambar 4 menunjukkan vibrasi kerangka hasil sintesis pada berbagai suhu dan waktu hidrotermal. Data selengkapnya tercantum pada Tabel 2. Berdasarkan data pada Tabel 2 dan diperkuat dengan Gambar 4 ditunjukkan bahwa hasil sintesis 
yang dilakukan pada $120^{\circ} \mathrm{C}$ selama 72 jam (120-72) telah menunjukkan adanya pita serapan khas pada bilangan gelombang 546 yang menunjukkan adanya cincin 5 dari struktur pentasil, namun tidak tampak adanya pita serapan pada bilangan gelombang sekitar $1220 \mathrm{~cm}^{-1}$. Hal ini menunjukkan sintesis dengan suhu hidrotermal $120^{\circ} \mathrm{C}$ selama 72 jam telah terbentuk ZSM-5 tetapi pembentukannya belum sempurna. Terbentuknya ZSM-5 ditandai dengan munculnya pita serapan khas MFI pada bilangan gelombang sekitar 550 dan $1220 \mathrm{~cm}^{-1}$. Pita serapan pada bilangan gelombang sekitar $550 \mathrm{~cm}^{-1}$ menunjukkan adanya cincin 5 dari struktur zeolit pentasil (D5R), sedangkan pita serapan pada bilangan gelombang sekitar $1220 \mathrm{~cm}^{-1}$ menunjukkan adanya vibrasi ulur Si-O-T denganT adalah Si atau Al

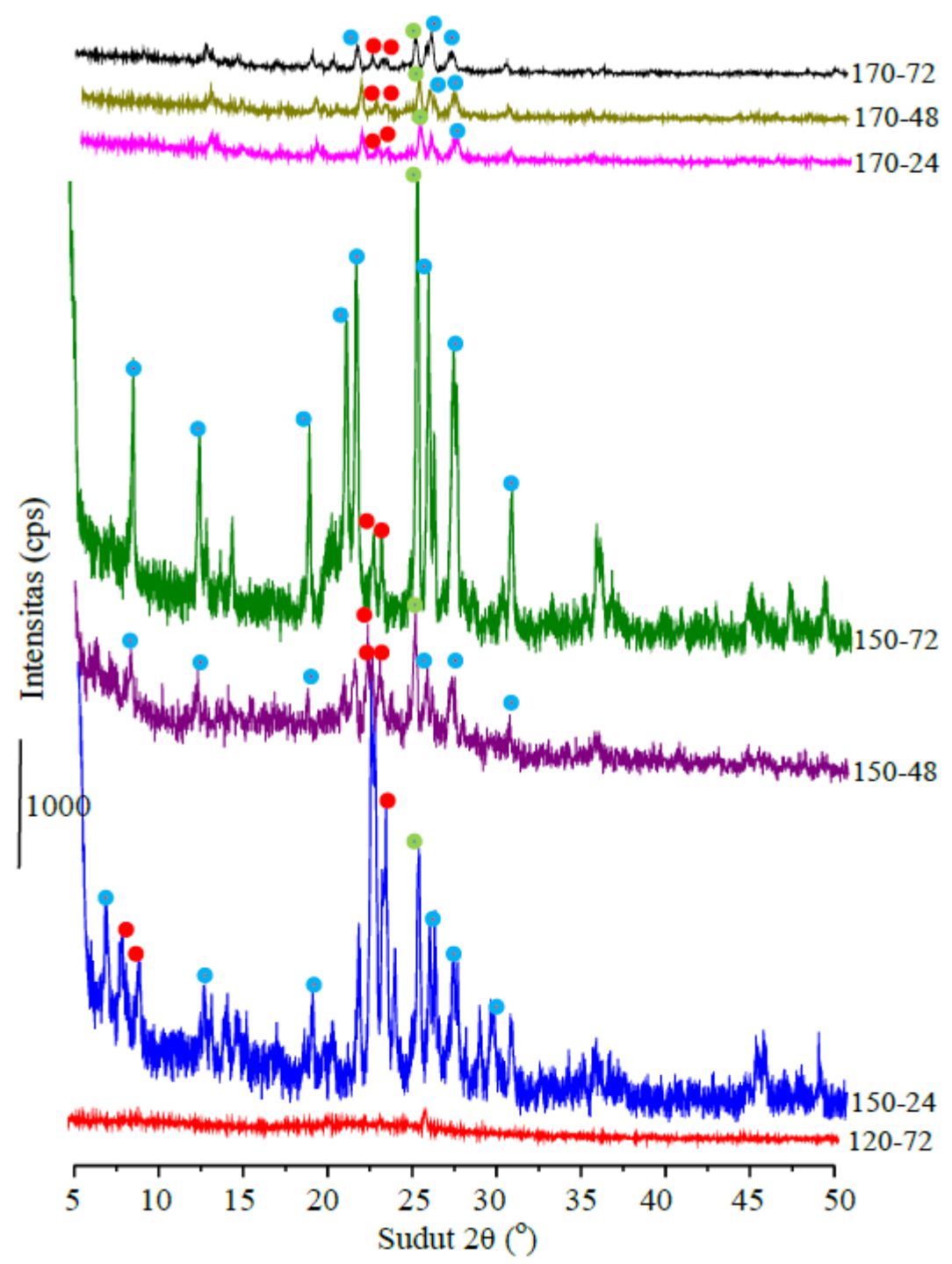

Gambar 2. Pola difraksi sinar-X hasil sintesis (•kuarsa, •ZSM-5 dan •mordenit)

Berdasarkan Tabel 4 ditunjukkan pula bahwa hasil sintesis pada $150^{\circ} \mathrm{C}$ selama 24 , 48, dan 72 jam menunjukkan terbentuknya pita khas untuk MFI yang mencirikan ZSM-5, demikian juga hasil sintesis pada $170^{\circ} \mathrm{C}$ selama 24,48 , dan 72 jam. Namun pada hasil sintesis pada $170^{\circ} \mathrm{C}$ selama 24 ,
48, dan 72 tidak hanya menunjukkan terbentuknya ZSM-5, karena semua hasil muncul pita vibrasi ulur simetri internal sekitar $700^{\circ} \mathrm{C}$ yang menunjukkan pita serapan mordenit ( $\mathrm{Li}$ and $\mathrm{Wu}, 2003$ ). Hal ini juga dapat dilihat pada Gambar 4. Berdasarkan spektra yang tercantum pada 
Gambar 4 ditunjukkan bahwa pita serapan ZSM-5 sangat rendah dan jauh lebih kecil dibandingkan sintesis pada suhu $150^{\circ} \mathrm{C}$.

Untuk mengetahui pori padatan hasil sintesis dilakukan dengan adsorpsi/desorpsi nitrogen. Pada Gambar 5 disampaikan hanya satu hasil analisis pori hasil sintesis pada $170^{\circ} \mathrm{C}$ selama 48 , yang menunjukkan bahwa kurva adsorpsi/desorpsi nitrogen sesuai dengan tipe I untuk padatan mikropori, yang tampak adsorpsi dimulai pada tekanan rendah $\mathrm{P} / \mathrm{P}_{\mathrm{o}}=0,0098$ meningkat tajam ke $\mathrm{P} / \mathrm{P}_{\mathrm{o}}=0,0689$ kemudian linier serta tidak ada loop histeresis. Pada tabel yang disisipkan ditunjukkan bahwa luas permukaan sampel hampir keseluruhan mikropori, dengan volume pori yang sangat kecil, yaitu hanya $0,004 \mathrm{~cm}^{3} / \mathrm{g}$.

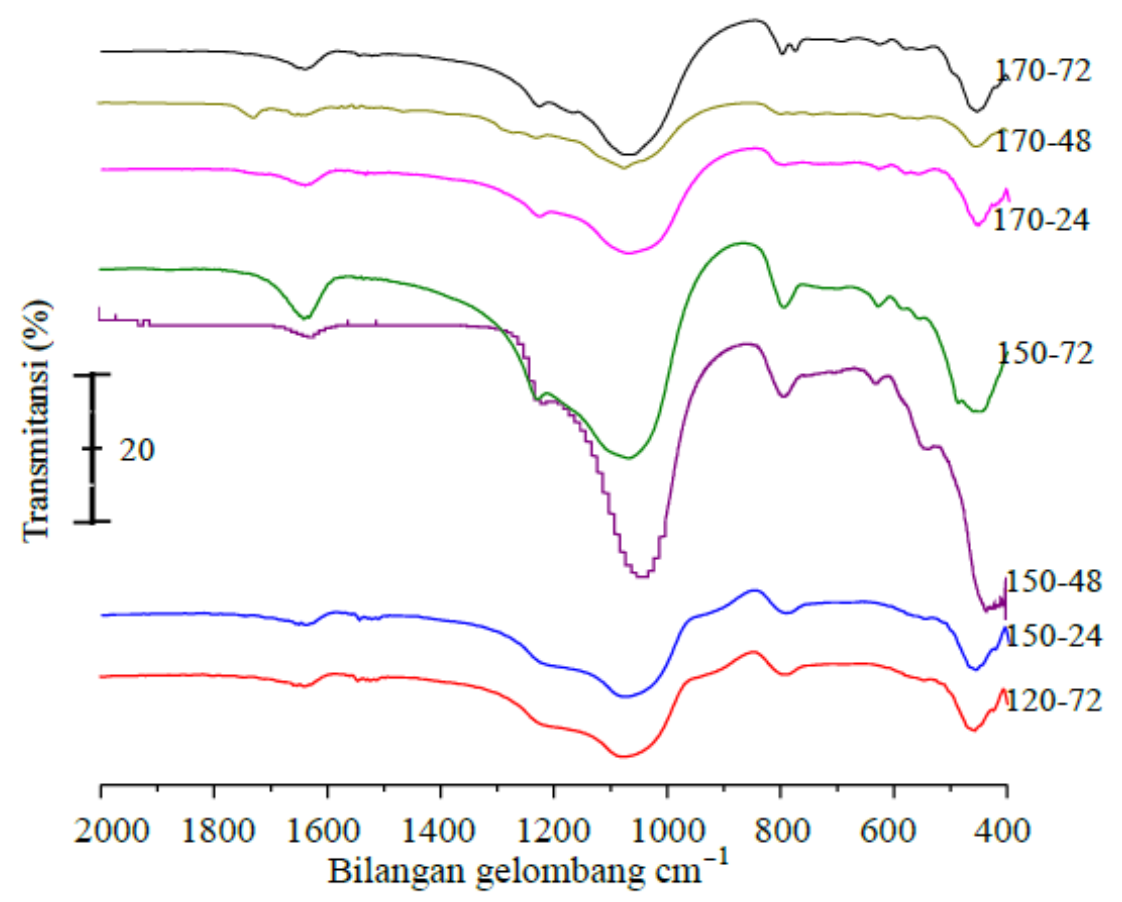

Gambar 4. Spektra FTIR hasil sintesis ZSM-5 pada suhu $120^{\circ} \mathrm{C}, 150^{\circ}$, dan $170^{\circ} \mathrm{C}$

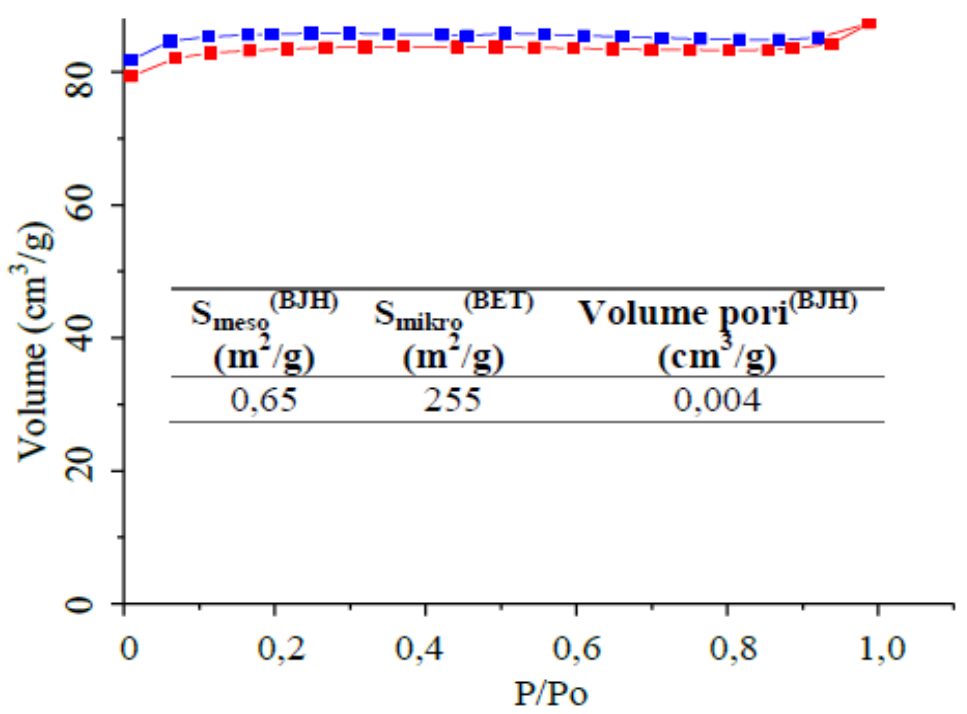

Gambar 5. Kurva adsorpsi/desorpsi nitrogen sampel hasil sintesis 


\section{Kesimpulan}

Sintesis ZSM-5 dari metakaolin terdealuminasi dapat dilakukan pada suhu $150^{\circ} \mathrm{C}$ atau lebih selama 24 jam atau lebih, tetapi belum dihasilkan ZSM-5 murni, karena masih mengandung kuarsa dan mordenit. Sintesis pada suhu $150^{\circ} \mathrm{C}$ selama 24 jam menghasilkan ZSM-5 relatif paling sedikit pengotornya. Sintesis pada suhu $150^{\circ} \mathrm{C}$ menghasilkan kristal yang relatif lebih baik dibandingkan sintesis pada $170^{\circ} \mathrm{C}$, karena sistesis pada

\section{Daftar Pustaka}

Ali, I., Hassan, A., Shabaan, S., El-Nasser, K., 2017, Synthesis and characterization of composite catalysts Cr/ZSM-5 and their effects toward photocatalytic degradation of p-nitrophenol, Arabian Journal of Chemistry, 10, S2106-S2114

Ayele, L., Pariente, J.P., Chebude, Y., Diaz, I., 2015, Synthesis of Zeolite A from Ethiopian Kaolin, Microporous and Mesoporous, 215, 29-36

Biligetu, T., Wang, Y., Nishitoba, T., Otomo, R., Park, S., Mochizuki, H., Kondo, J.N., Tatsumi, T., Yoko, T., 2017, Al distribution and catalytic performance of ZSM-5 zeolites synthesized with various alcohols, , Journal of Catalysts, 353, 1-10

Cheng, H., Liu, Q., Mac, S., Frost, R.L., 2012, The thermal Behavior of Kaolinite Intercalation Complexes-A Review, Thermochimica Acta, 545, 113

Feng, H., Chuyi, L., Hong, S., 2008, Effect of Calcination Temperature of Kaolin Microspheres on the In Situ Synthesis of ZSM-5, Catalyst Letters, 129, 7178

Frantz, T.S., Ruiz, W.A., da Rosa, C.A., Mortola, V.B., 2016, Synthesis of ZSM-5 with High Sodium Content for $\mathrm{CO}_{2}$ Adsorption, Microporous and Mesoporous Materials, 222, 209-217 $170^{\circ} \mathrm{C}$ menghasilkan padatan kristal dengan puncak jauh lebih pendek pada pola difraksinya, dan mengandung pengotor mordenit lebih banyak. Hasil sintesis menunjukkan bahwa padatan yang terbentuk adalah mikropori.

\section{Ucapan terima kasih}

Terima kepada Menteri Riset Teknologi dan Pendidikan Tinggi yang telah memberi dana riset PUPT, Nomor: 018/SP2H/LT/DRPM/2016, Tanggal 17 Februari 2016.

Hartati, H., Widati, A.A., Setyawati, H., Fitri, S., 2016, Preparation of Hierarchical ZSM-5 from Indonesian Kaolin by Adding Silica, Chemistry \& Chemical Technology, Vol. 10, No. 1, 87-90

Hartati, H., Widati, A.A., Dewi, T.K., Prasetyoko, D., 2017, Direct Synthesis of Highly Crystalline ZSM5 from Indonesian Kaolin, Bulletin of Chemical Reaction Engineering \& Catalysis, 12 (2), 251-255

Hartati, Akustia, A., Permana, I., Prasetyoko, D., 2016, Three-step Crystallization in Synthesis of ZSM-5 without Organic Template, AIP Conference Proceedings, 1718, 060002-1 - 060002-8

Hartati, Widati, A.A., Kristanti, A.N., Purwaningsih, A., Alfiani, 2017, Organic Template Free Synthesis of ZSM-5 from Calcinated Indonesian Kaolin, AIP Conference Proceedings, 1888, 020024-1 - 020024-6

Jiao, Y., Fan, X., Perdjon, M., Yang, Z., Zhang, J.,2017, Vapor-phase transport (VPT) modification of ZSM-5/SiC foam catalyst using TPAOH vapor to improve the methanol-to-propylene (MTP) reaction, Applied Catalysis A, General, 545, 104-112

Johnson, E.B.G., Arshad, S.E., 2014, Hydrothermally Synthesized Zeolites based on Kaolinite: A Review, Applied Clay Science 97-98, 215-221 
Li, C. and $\mathrm{Wu}, \mathrm{Z} ., \quad 2003$, Microporous Materials Characterized by Vibrational Spectroscopies, dalam Handbook of Zeolites Science and Technology, Marcel and Dekker, New York

Liua, Q., Wena, D., Yang, Y., Fei, Z., Zhanga, Z., Chena, X., Tanga,J., Cuia, M., Qiaoa, X., 2018, Enhanced catalytic performance for light-olefins production from chloromethane over hierarchical porous ZSM-5 zeolite synthesized by a growth-inhibition strategy, Applied Surface Science, 435, 945-952

Mohiuddin, E., Isa, Y.M., Mdleleni, M.M., Sincadu, N., Key, D., Tshabalala, T., 2016, Synthesis of ZSM-5 from impure and beneficiated Grahamstown kaolin:Effect of kaolinite content, crystallisation temperatures and time, Applied Clay Science, 119, 213-221

Niu, X. , Gao, J., Wang, K., Miao,Q., Dong, M., Wang, G., Fan, W., Qin, Z., Wang, J., 2017, Influence of crystal size on the catalytic performance of H-ZSM-5 and Zn/H-ZSM-5 in the conversion of methanol to aromatics, Fuel Processing Technology, 157, 99-107
Panpa, W., Jinawath, S., 2009, Synthesis of ZSM-5 zeolite and silicalite from rice husk ash, Applied Catalysis B: Environmental, 90 (3-4), 389-394

Pan, F., Lu, X., Wang, Y., Chen, S., Wang, T., Yan, Y., 2014, Organic Templatefree Synthesis of ZSM-5 Zeolite from Coal-Series Kaolinite, Materials Letters, 115, 5-8

Prasetyoko, D., Ayunanda, N., Fansuri, H., Hartanto, H., Ramli, Z., 2012, Phase Transformation of Rice Husk Ash in the Synthesis of ZSM-5 without Organic Template, ITB J. Sci., 44 A (3), 250-262

Rustam, Ediati, R., Septiyana, B., Zein, Y.M., Bahruji, H., Qoniah, I., Hartati, Nur, H., Prasetyoko, D., 2017, Direct synthesis of ZSM-5 from kaolin and the influence of organic template, Malaysian Journal of Fundamental and Applied Sciences, 13(2), 137-142

Wu, T., Chen, S., Yuan, G., Cao, Y., Su, K., 2017, Enhanced catalytic performance in butylene cracking by hierarchical surface silicon-rich ZSM5, Fuel Processing Technology 167, 162-170 